Check for updates

The BMJ

Cite this as: $B M J 2021 ; 372: \mathrm{n} 723$ http://dx.doi.org/10.1136/bmi.n723 Published: 16 March 2021

\title{
Covid vaccine could be rolled out to children by autumn
}

\section{Elisabeth Mahase}

Some covid-19 vaccines could be rolled out to children later this year, as early, real world reports indicate few adverse events.

While the global rollout of vaccines to adults continues apace, with more than 359 million doses of vaccines against SARS-CoV-2 administered as at 15 March, health leaders and researchers have been turning their attention to children.

In Israel, where 106 vaccine doses have been administered for every 100 adults, the health ministry recently recommended vaccinating some older children with underlying conditions that make them vulnerable to the effects of the virus, such as cystic fibrosis. Some 600 children aged between 12 and 16 have been given the Pfizer vaccine, and early results reported in the Guardian have indicated no serious side effects. ${ }^{1}$

The head of Israel's vaccine taskforce, Boaz Lev, said, "We didn't see any major side effects, and even minor [ones] are quite rare. This is encouraging."

\section{Trials in children}

Although these vaccinations were not part of a clinical trial, trials are currently under way to test the Pfizer, Moderna, and Oxford-AstraZeneca vaccines in children. Pfizer has enrolled more than 2000 children aged 12-15 for a trial that was announced in October. It also expects to run a second trial in children aged 5-11 years. ${ }^{2}$ Pfizer's chief executive, Albert Bourla, told Reuters in March that he expected younger teens to be eligible for coronavirus vaccination in the autumn and primary school children by the end of the year. ${ }^{3}$

In December Moderna announced that it would be testing its vaccine in 3000 young people aged 12-17, half of whom would receive two shots of the vaccine four weeks apart, while the half would get a placebo. ${ }^{4}$

Anthony Fauci, director of the US National Institute of Allergy and Infectious Diseases, has said that high school students across the country should be able to get a vaccine in the autumn. ${ }^{5}$ The US has so far authorised the rollout of the Pfizer, Moderna, and Johnson \& Johnson vaccines.

The Oxford research group is also testing its vaccine in children aged 6-17, in a trial funded by the National Institute for Health Research and AstraZeneca. The phase II trial, which began in February, will enrol 300 volunteers. Up to 240 of these participants will receive the covid-19 vaccine, while the rest will be given a control meningitis vaccine-being used as it is expected to produce similar reactions, such as soreness at the injection site.

The chief investigator on the Oxford vaccine trial, Andrew Pollard, a professor of paediatric infection and immunity, said, "While most children are relatively unaffected by coronavirus and are unlikely to become unwell with the infection, it is important to establish the safety and immune response to the vaccine in children and young people as some children may benefit from vaccination.”

\section{Transmission}

Beate Kampmann, director of the London School of Hygiene and Tropical Medicine's Vaccine Centre, told The BMJ that while most children were not at risk of severe covid-19 illness, they may have an important role when it comes to transmission.

"To include children in the vaccination programme is essentially a question of their role in transmission of the virus. They do not usually have severe disease manifestations, with a few exceptions, usually related to comorbidities. The more adults we can protect with the vaccines the less the vaccination of children would matter. However, to achieve as much suppression of viral circulation and to get to community immunity which can then suppress transmission and evolution of new variants, it could be justified," she said, adding that it was unlikely that children under 5 would be vaccinated.

Commenting on what evidence would be needed to extend authorisation to children, Kampmann, who is a professor of paediatric infection and immunity, said, "We need to exclude side effects in children, and we need to show that the vaccines induce a similar immune profile as we have seen in the already highly protected adults - then the vaccines could be approved on the ground of so called immunobridging."

\footnotetext{
Holmes 0. Israel says 600 children given Covid jab had no serious side-effects. Guardian. 10 Mar 2021. https://www.theguardian.com/society/2021/mar/10/israel-says-600-children-given-covid-jab-had-no-seriousside-effects

2 Pfizer. A phase 3 study to evaluate the safety, tolerability, and immunogenicity of multiple production lots and dose levels of BNT162b2 against covid-19 in healthy participants: NCT04713553. https://www.pfiz er.com/science/find-a-trial/nct04713553.

3 Pfizer CEO expects younger teens to be eligible for covid-19 vaccines in fall. Reuters. 11 Mar 2021. https://globalnews.ca/news/7690900/pfizerchildren-coronavirus-vaccination7690900.

4 A study to evaluate the safety, reactogenicity, and effectiveness of mRNA-1273 vaccine in adolescents 12 to $<18$ years old to prevent covid-19 (TeenCove). ClinicalTrials.Gov. https://clinicaltrials.gov/ct2/show/NCT04649151.

5 Pitofsky M. Fauci predicts high schoolers will receive coronavirus vaccinations this fall. The Hill. 7 Mar 2021. https://thehill.com/policy/healthcare/542039-fauci-predicts-high-schoolers-to-receive-coronavirus-vaccinations-this-fall.
}

This article is made freely available for use in accordance with BMJ's website terms and conditions for the duration of the covid-19 pandemic or until otherwise determined by BMJ. You may use, download and print the article for any lawful, non-commercial purpose (including text and data mining) provided that all copyright notices and trade marks are retained. 